\title{
Peptide-Based Hydrogels and Nanogels for Delivery of Doxorubicin
}

This article was published in the following Dove Press journal:

International Journal of Nanomedicine

\author{
Enrico Gallo' \\ Carlo Diaferia $\left(\mathbb{D}^{2}\right.$ \\ Elisabetta Rosa ${ }^{2}$ \\ Giovanni Smaldone' \\ Giancarlo Morelli ${ }^{2}$ \\ Antonella Accardo (iD) ${ }^{2}$ \\ 'IRCCS SDN, Naples, 80I43, Italy; \\ ${ }^{2}$ Department of Pharmacy and Research \\ Centre on Bioactive Peptides (CIRPeB), \\ University of Naples "Federico II", \\ Naples, 80 I34, Italy
}

Introduction: The clinical use of the antitumoral drug doxorubicin (Dox) is reduced by its dose-limiting toxicity, related to cardiotoxic side effects and myelosuppression. In order to overcome these drawbacks, here we describe the synthesis, the structural characterization and the in vitro cytotoxicity assays of hydrogels (HGs) and nanogels (NGs) based on short peptide sequences loaded with Dox or with its liposomal formulation, Doxil.

Methods: Fmoc-FF alone or in combination with (FY)3 or PEG8-(FY)3 peptides, at two different ratios $(1 / 1$ and $2 / 1 \mathrm{v} / \mathrm{v})$, were used for HGs and NGs formulations. HGs were prepared according to the "solvent-switch" method, whereas NGs were obtained through HG submicronition by the top-down methodology in presence of $\mathrm{TWEEN}^{\circledR} 60$ and $\operatorname{SPAN}^{\circledR} 60$ as stabilizing agents. HGs gelation kinetics were assessed by Circular Dichroism (CD). Stability and size of NGs were studied using Dynamic Light Scattering (DLS) measurements. Cell viability of empty and filled Dox HGs and NGs was evaluated on MDA-MB-231 breast cancer cells. Moreover, cell internalization of the drug was evaluated using immunofluorescence assays.

Results: Dox filled hydrogels exhibit a high drug loading content (DLC $=0.440$ ), without syneresis after 10 days. Gelation kinetics (20-40 $\mathrm{min}$ ) and the drug release (16-28\%) over time of HGs were found dependent on relative peptide composition. Dox filled NGs exhibit a DLC of 0.137 and a low drug release (20-40\%) after $72 \mathrm{~h}$. Empty HGs and NGs show a high cell viability ( $>95 \%)$, whereas Dox loaded ones significantly reduce cell viability after $24 \mathrm{~h}(49-57 \%)$ and $72 \mathrm{~h}(7-25 \%)$ of incubation, respectively. Immunofluorescence assays evidenced a different cell localization for Dox delivered through HGs and NGs with respect to the free drug.

Discussion: A modulation of the Dox release can be obtained by changing the ratios of the peptide components. The different cellular localization of the drug loaded into HGs and NGs suggests an alternative internalization mechanism. The high DLC, the low drug release and preliminary in vitro results suggest a potential employment of peptide-based HGs and NGs as drug delivery tools.

Keywords: hydrogels, nanogels, drug delivery, peptide materials, doxorubicin, in vitro assays

\section{Introduction}

Nowadays, cancer remains one of the leading causes of mortality worldwide, affecting more than 10 million new patients every year. Among cancerous diseases, breast cancer is the most common one for women in the United States with more than 200,000 newly diagnosed cases for year. ${ }^{1}$ Current treatment options include surgical resection, radiation, and chemotherapy. Chemotherapeutic regime establishes the treatment of patients with drugs (doxorubicin, docetaxel, paclitaxel, and tamoxifen) alone or in combination. ${ }^{2}$ Doxorubicin (Dox), also known as Adriamycin, is a natural antitumor antibiotic of the anthracycline class, which
Correspondence: Antonella Accardo Department of Pharmacy and Research Centre on Bioactive Peptides (CIRPeB), University of Naples "Federico II", Via Mezzocannone 16, Naples, 80134, Italy

Tel +390812532045

$\mathrm{Fax}+390812536642$

Email antonella.accardo@unina.it
International Journal of Nanomedicine 2021:16 16|7-1630

1617 
works as DNA intercalating agent and as an inhibitor of topoisomerase II. $^{3}$ Despite its therapeutic potentiality, clinical use of Dox is hampered by its dose-limiting toxicity, represented by myelosuppression and cardiotoxic side effects, which cause increased cardiovascular risks. ${ }^{4}$ In addition, Dox-mediated cardiotoxicity was found to be cumulative and dose-dependent, with heart suffering from the very first dose and then with accumulative damage for each following anthracycline cycle. ${ }^{5,6}$ In order to overcome these drawbacks, Dox encapsulating nanoformulations has been proposed as an alternative strategy for its administration. Currently, two doxorubicin liposomal formulations, Caelyx ${ }^{\circledR} /$ Doxil $^{\circledR}$ and Myocet $^{\circledR}$, and their bioequivalent formulations, are available in the clinic. $^{7,8}$ The liposomal spatial confinement of Dox allows altering biodistribution of the drug, minimizing its toxicity, increasing the half-life and the therapeutic index and improving the pharmaceutical profile, thus leading to increased patient compliance. ${ }^{9,10}$

In the last years, other typologies of nanosized structures, including polymer-based aggregates, ${ }^{11}$ nanofibers, ${ }^{12}$ nanodisks, ${ }^{13}$ gold nanoparticles, ${ }^{14}$ graphene and graphene oxide ${ }^{15,16}$ and hydrogels (HGs), were evaluated and studied as novel Dox-delivery tools. HGs are self-supporting materials, structured as supramolecular hydrophilic networks associated with the construction of space-spanning structures characterized by a nonNewtonian behavior. The hydrophilic nature of HGs constituents allows entrapping a high volume of biological fluids and water during the swelling process. ${ }^{17} 3 \mathrm{D}$ connectivity in physical cross-linked HGs is related to aggregation/interaction of molecules, cooperating through non-covalent interactions or via chemical irreversible bonds. Due to their unique structure, HGs have been exploited as versatile tools for many different biomedical applications (such as 3D-extracellular matrices for wound healing systems, ${ }^{18}$ cell support for tissue engineering and regeneration, ${ }^{19,20}$ protein mimetics, ${ }^{21}$ ophthalmic compatible materials, ${ }^{22}$ and drug delivery systems ${ }^{23}$ ). Submicronization of HGs by top-down methodologies gives the possibility to generate smaller hydrogel particles with a size in the nano-range. ${ }^{24}$ These hydrogel nanoparticles, named nanogels (NGs), combine the same hydrated inner network of hydrogels with the size of injectable nanoparticles, such as micelles and liposomes. $^{25}$ Due to their size, nanogel formulations could achieve a fast renal clearance, a feasible penetration through tissue barriers and a prolonged circulation time in the blood stream.

Hydrogels and nanogels can be prepared using synthetic $^{26-28}$ or natural polymers ${ }^{29-32}$ or peptide sequences. ${ }^{33,34}$ With respect to polymers, peptides exhibit several advantages such as high biocompatibility, biodegradability and tunability. Fmoc-FF $\left(\mathrm{N}^{\alpha}\right.$ fluorenylmethyloxycarbonyl diphenylalanine) hydrogelator (Figure 1) represents one of the most studied peptide sequences for hydrogels formulation, thanks to its capability to gelificate under physiological conditions, required for biomedical applications. ${ }^{35-37}$ Recently, we have described the preparation of pure Fmoc-FF and mixed Fmoc-FF/(FY)3 and Fmoc-FF/PEG 8 -(FY)3 (at 2/ 1 or $1 / 1, \mathrm{v} / \mathrm{v}$ ) hydrogels. ${ }^{38} \mathrm{PEG}_{8}-(\mathrm{FY}) 3$ and $(\mathrm{FY}) 3$ are the PEGylated and the non-PEGylated versions of the (FY)3 hexapeptide, this latter containing as peptide framework the alternation of three tyrosine (Y) and three phenylalanine (F) residues. ${ }^{39}$ The rheological characterization of the mixed gels pointed out that the presence of PEG and its relative amount into the mixed gel causes a slowing down of the gelation kinetic and a decrease of the gel rigidity. This different behavior was attributed to the high flexibility and conformational freedom of the PEG chain in the mixed hydrogel. Independently of their composition, all the gels showed an in vitro cell viability higher than $95 \%$ after $24 \mathrm{~h}$ of incubation, thus suggesting their potential applications in the biomedical field.

Here we describe the Dox loading capability of hydrogels and nanogels (both pure and mixed) and their drug release properties over time. We also report the in vitro cytotoxicity of both empty and Dox filled HGs and NGs on MDA-MB-231 breast cancer cell line representative of Triple Negative Breast Cancer (TNBC), the most aggressive breast cancer subtype. ${ }^{40}$ These results are compared with empty and Dox filled nanogel formulations, ${ }^{41}$ obtained sub-micronizing hydrogels by a top-down method. We also checked the capability of peptide-based hydrogels to encapsulate supramolecular nanodrugs and we studied their effective cytotoxicity on cells. For instance, as nanodrug we chose the liposomal doxorubicin formulation Doxil. This strategy could allow to obtain a composite drug delivery platform for a multi-stage delivery of Dox.

\section{Materials and Methods}

Protected $\mathrm{N}^{\alpha}$-Fmoc-amino acid derivatives, coupling reagents, and Rink amide MBHA (4-methylbenzhydrylamine) resin 


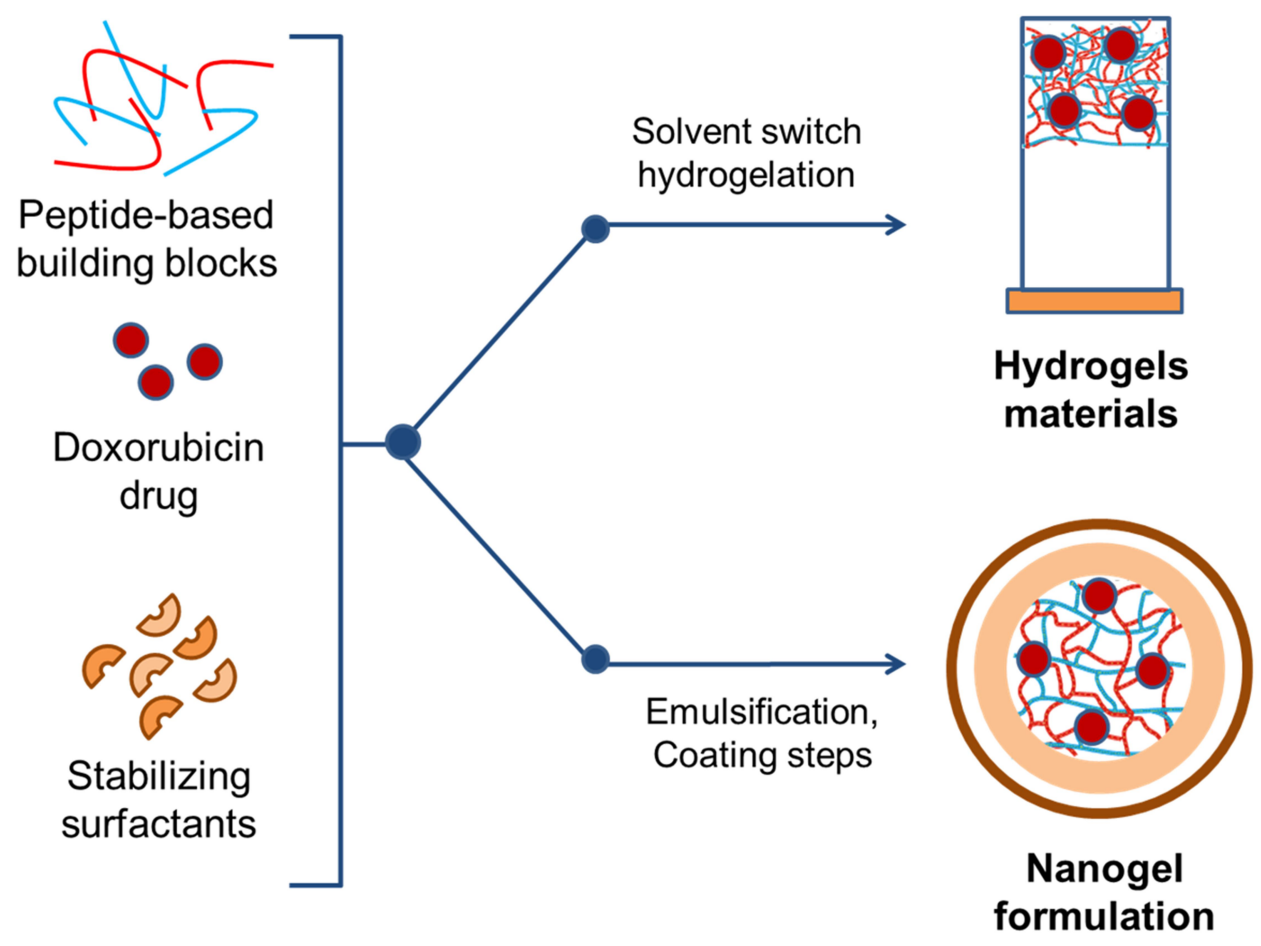

Peptide components legend

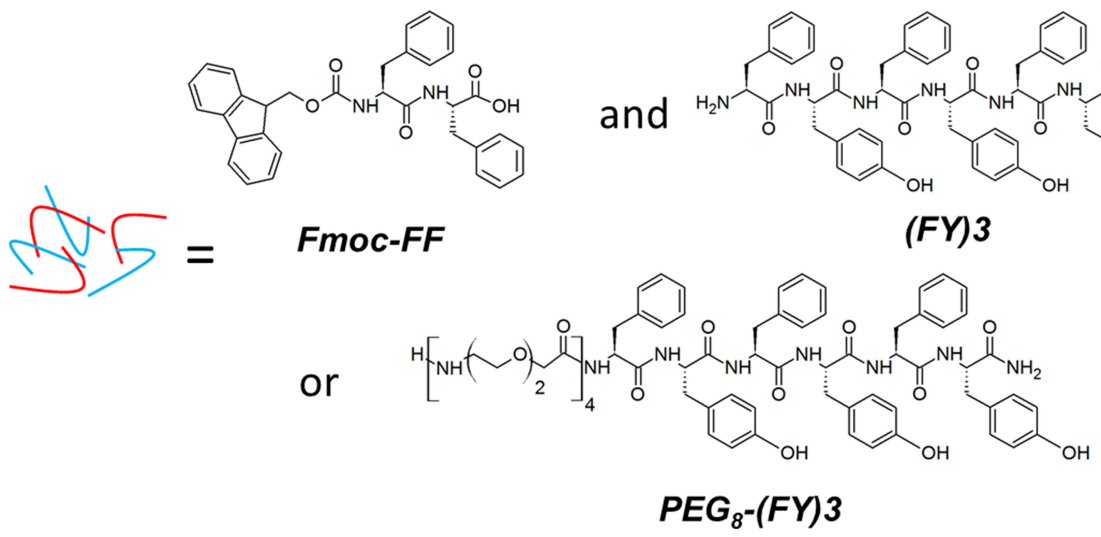

Figure I Schematic representation of components and methodologies for the formulation of HGs and NGs. Chemical formulas for peptide-based components are reported in the legend.

were purchased from Calbiochem-Novabiochem (Laufelfingen, Switzerland). The monodisperse Fmoc8-amino-3,6-dioxaoctanoic acid (Fmoc- AdOO-OH, PEG2) was purchased from Neosystem (Strasbourg, France). Lyophilized Fmoc-FF powder was purchased from Bachem (Bubendorf, Switzerland). Doxorubicin chlorohydrate (Dox. $\mathrm{HCl}$ ) was purchased from Sigma Aldrich (Milan, Italy). Pegylated liposomal Dox (commercial name of Doxil) vials were kindly gifted by the Italian Cancer Institute in Naples (Italy) "Fondazione G. Pascale". TWEEN ${ }^{\circledR} 60, \operatorname{SPAN}^{\circledR} 60$, and all other chemicals and solvents were purchased from Sigma-
Aldrich, Fluka (Bucks, Switzerland) or LabScan (Stillorgan, Dublin, Ireland) and were used as received unless otherwise stated. All solutions were obtained by weight using doubly distilled water as a solvent. UV-Vis spectra were recorded on a Thermo Fisher Scientific Inc (Wilmington, Delaware USA) Nanodrop 2000c, equipped with a $1.0 \mathrm{~cm}$ quartz cuvette (Hellma).

\section{Peptide Synthesis}

(FY)3 and its PEGylated analogue $\mathrm{PEG}_{8}-(\mathrm{FY}) 3$ peptide derivative were synthesized by peptide solid phase 
synthesis (SPPS) procedures with a Fmoc/tBu chemistry approach as previously described ${ }^{39,42,43}$ and purified by RP-HPLC chromatography.

\section{Hydrogels and Nanogels Formulation}

Pure Fmoc-FF hydrogel and mixed Fmoc-FF/PEG ${ }_{8}-(\mathrm{FY}) 3$ and Fmoc-FF/(FY)3 hydrogels ( $1 / 1$ or $2 / 1$, v/v) were prepared as previously described using the "solvent-switch method"44 to a final concentration of $0.5 \mathrm{wt} \%{ }^{38}$ Briefly, each peptide component (Fmoc-FF, (FY) 3 and $\mathrm{PEG}_{8}$-(FY) 3) was dissolved in dimethyl sulfoxide (DMSO) to a final concentration of $100 \mathrm{mg} / \mathrm{mL}$. Pure Fmoc-FF hydrogel (400 $\mu \mathrm{L}$ ) was obtained by diluting $20 \mu \mathrm{L}$ of the Fmoc-FF stock solution with $380 \mu \mathrm{L}$ of double distilled water under stirring ( 5 seconds). Preparation of all the mixed hydrogels was achieved analogously, by combining the peptides stock solutions at the desired volume/volume ratios. Pure and mixed nanogel formulations were prepared as previously described according to the top-down method. ${ }^{41}$ Briefly, the gel disk obtained into a silicone mold was homogenized at $35,000 \mathrm{~min}^{-1}$ for 5 min into $4 \mathrm{~mL}$ of an aqueous solution containing TWEEN 60/SPAN 60 at a w/ w ratio of 52/48 $\left(3.10^{-5} \mathrm{~mol}\right)$ for pure Fmoc-FF NGs and only TWEEN $60\left(3.10^{-5} \mathrm{~mol}\right)$ for mixed Fmoc-FF/(FY)3 NGs. The resulting suspensions were then tip sonicated for 5 min at $9 \mathrm{~W}$.

\section{Doxorubicin Filled Hydrogels and Nanogels}

Dox filled hydrogels were prepared as described above by adding $380 \mu \mathrm{L}$ of an aqueous Dox solution at a concentration of $4 \cdot 0 \cdot 10^{-3} \mathrm{~mol} \mathrm{~L}^{-1}$ to the peptide stock solutions. Dox filled nanogels were prepared according to the top-down methodology as previously described. ${ }^{41}$ Shorty, a disk of pure or mixed hydrogel loaded with Dox was prepared adding the stock solution of peptide $(100 \mathrm{mg} / \mathrm{mL})$ to $900 \mu \mathrm{L}$ of an aqueous solution of Dox $\left(0.018 \mathrm{~mol} \mathrm{~L}^{-1}\right)$, which allows to reach a drug weight/lipid weight ratio of 0.250 . Then, the hydrogel disk was homogenized, and tip sonicated into $4 \mathrm{~mL}$ of TWEEN 60/SPAN 60 mixture or TWEEN 60 , according to the empty formulation. Purification of Dox filled nanogels from free Dox was achieved by gel filtration on a pre-packed column Sephadex G-50. The drug loading content (DLC), defined as $\mathrm{g}_{\text {Dox encapsulated }} / \mathrm{g}_{\text {(surfactant+peptide), was quantified by }}$ subtraction of the free Dox from the total amount of loaded Dox. The Dox concentration was determined by UV-Vis spectroscopy using calibration curves obtained by measuring absorbance at $\lambda=480 \mathrm{~nm}$.

\section{Doxil Filled Hydrogels}

Doxil filled hydrogels were prepared analogously to Dox filled ones, by adding $380 \mu \mathrm{L}$ of the commercial Doxil solution opportunely diluted in order to achieve the same Dox concentration $\left(4.0 .10^{-3} \mathrm{~mol} \mathrm{~L}^{-1}\right)$ that was in the HGs.

\section{Circular Dichroism (CD)}

Far-UV CD spectra of Dox filled hydrogels and nanogels were collected on a Jasco J-810 spectropolarimeter equipped with a NesLab RTE111 thermal controller unit at $25^{\circ} \mathrm{C} .100 \mu \mathrm{L}$ of a hydrated DMSO stock solution (immediately after its generation) were placed on a $0.1 \mathrm{~mm}$ quartz cell. The measurements were recorded as function of the time (every 8 minutes) in the range of wavelength between 300 and $200 \mathrm{~nm}$. Other experimental settings were: scan speed $=50 \mathrm{~nm} \mathrm{~min}{ }^{-1}$, sensitivity $=10 \mathrm{mdeg}$, time constant $=16 \mathrm{~s}$, bandwidth $=1 \mathrm{~nm}$. Each spectrum was obtained by averaging three scans. All the spectra are reported in optical density (O.D.).

\section{Confocal Analysis}

For confocal microscopy, Dox filled hydrogels were dropcasted and spread on a glass slide, air-dried at room temperature, and examined by confocal microscopy. Confocal images were obtained with a Leica TCS-SMDSP5 confocal microscope $\left(\lambda_{\text {exc }}=488 \mathrm{~nm}\right.$ and $\lambda_{\mathrm{em}}=$ 505-600 nm). 0.8- $\mu \mathrm{m}$ thick optical slices were acquired with a $63 \times$ or $40 \times / 1.4$ NA objective.

\section{Dynamic Light Scattering (DLS) Measurements}

Mean diameters and diffusion coefficients (D) of empty and Dox filled NGs were estimated by DLS using a Zetasizer Nano ZS (Malvern Instruments, Westborough, MA). Instrumental settings for the measurements are a backscatter detector at $173^{\circ}$ in automatic modality, room temperature and disposable sizing cuvette as cell. DLS measurements in triplicate were carried out on aqueous samples after centrifugation at room temperature at 13,000 rpm for 5 minutes. 


\section{Dox Release from Hydrogels and Nanogels}

Dox and Doxil release from hydrogels were evaluated in a conic tube $(1.5 \mathrm{~mL})$ using $400 \mu \mathrm{L}$ of drug filled hydrogels ( $0.5 \% \mathrm{wt}$ ) adding, on the top of them, $800 \mu \mathrm{L}$ of $0.100 \mathrm{~mol} \mathrm{~L}^{-1}$ phosphate buffer. At each time-point, $400 \mu \mathrm{L}$ of this solution was removed and replaced with an equal fresh aliquot. Released Dox was quantified by UV-Vis spectrum of the supernatant at $480 \mathrm{~nm}$. All the release experiments were performed in triplicates. The extent of Dox release was reported as percentage of the ratio between the amount of released drug and the total quantity of drug initially loaded into hydrogels. Dox release from nanogels was achieved using the well-known dialysis method. ${ }^{45}$ Briefly, Dox loaded nanogel suspension $(1.0 \mathrm{~mL})$ was placed into a dialysis bag (MW cut-off $=3500 \mathrm{Da}$ ). This bag was immersed under stirring for $72 \mathrm{~h}$, at $37^{\circ} \mathrm{C}$ into $20 \mathrm{~mL}$ of phosphate buffer. Then, $2 \mathrm{~mL}$ of the dialyzed solution was replaced with an equal amount of fresh solution at different time points. Fluorescence measurements of each fraction of the dialyzed solution were recorded at room temperature with a spectrofluorophotometer Jasco (Model FP-750, Japan) in a quartz cell with $1.0 \mathrm{~cm}$ path length. The other settings were as follows: excitation and emission bandwidths $=5 \mathrm{~nm}$, recording speed $=125 \mathrm{~nm} /$ min, and excitation wavelength $=480 \mathrm{~nm}$, emission range from 490 to $700 \mathrm{~nm}$. The amount of doxorubicin contained in each fraction was estimated using an analytical titration curve previously recorded for the free Dox in the same spectral range. Analogously to HGs, Dox release profile from NGs was reported as percentage of released drug/total drug loaded into NGs.

\section{Cell Line}

Human breast cancer cell line MDA-MB-231 was obtained from IRCCS-SDN Biobank (10.5334/ojb.26) and growth in Dulbecco's Modified Medium (DMEM) supplemented with $10 \%$ fetal bovine serum (FBS) and $1 \%$ GlutaMAX. Cells were incubated at $37^{\circ} \mathrm{C}$ and $5 \%$ $\mathrm{CO}_{2}$ and seeded in T-25 culture flasks.

\section{Cell Viability Evaluation by MTT}

For MTT assays (Sigma Aldrich, Germany), MDA-MB -231 cells were seeded in 24-well plates at a density of 50 $\times 10^{4}$ per well. After $24 \mathrm{~h}$ free Dox at $1 \mu \mathrm{mol} \mathrm{L}{ }^{-1}$, nanogels and hydrogels (these latter preformed into a hollow plastic chamber sealed at one end with a porous membrane) were added to the wells. Cells were treated with the hydrogels for
$24 \mathrm{~h}$ and with nanogel solutions for $72 \mathrm{~h}$. At the end of the treatment, cell viability was assessed by the MTT assay. For the $\mathrm{IC}_{50}$ determination of Dox, MDA-MB-231 cells were seeded in 24-well plates at a density of $50 \times 10^{4}$ per well and treated with different concentrations $(0.25,0.5,1,2$ and 4 $\mu \mathrm{mol} \mathrm{L}{ }^{-1}$ ) of Dox for $24 \mathrm{~h}$. At the end of the treatment, cell viability was assessed by the MTT assay. In brief, MTT, dissolved in DMEM in the absence of phenol red (SigmaAldrich), was added to the cells at a final concentration of $0.5 \mathrm{mg} / \mathrm{mL}$. After $4 \mathrm{~h}$ incubation at $37^{\circ} \mathrm{C}$, the culture medium was removed, and the resulting formazan salts were dissolved by adding isopropanol containing $0.1 \mathrm{~mol} \mathrm{~L}-1$ $\mathrm{HCl}$ and $10 \%$ Triton-X100. Absorbance values of blue formazan were determined at $490 \mathrm{~nm}$ using an automatic plate reader (EL 800, Biotek). Cell survival was expressed as percentage of viable cells in the presence of hydrogels or nanogels, compared to control cells grown in their absence. MTT assay was repeated twice with similar results.

\section{Immunofluorescence Experiments}

MDA-MB-231 cells were treated for $24 \mathrm{~h}$ with $1 \mu \mathrm{mol} \mathrm{L}{ }^{-1}$ free Dox or $1.13 \mathrm{mmol} \mathrm{L}^{-1}$ Dox loaded Fmoc-FF/(FY)3 hydrogels and Fmoc-FF/(FY)3 nanogels. Cells were fixed at $-20^{\circ} \mathrm{C}$ for 15 minutes with a $-80^{\circ} \mathrm{C}$ pre-cooled solution of methanol/acetone $(1 / 1, \mathrm{v} / \mathrm{v})$. Subsequently, cells were subjected to blocking with solution of $3 \%(\mathrm{w} / \mathrm{v}) \mathrm{BSA}$ in PBS pH 7.4 at room temperature (RT). Anti B-actin (A2228, Sigma Aldrich) monoclonal antibody was diluted $1: 200$ in a solution of PBS $+1 \%(\mathrm{w} / \mathrm{v}) \mathrm{BSA}$ and then all slides were incubated for $4 \mathrm{~h}$ at $+4{ }^{\circ} \mathrm{C}$. After three washing steps in PBS for 5 minutes each, FITC-conjugated antimouse secondary antibody (ab7064, Abcam, UK) diluted $1: 400$ in a solution of PBS $+1 \%(w / v)$ BSA was incubated for $1 \mathrm{~h}$ at $4^{\circ} \mathrm{C}$ in the dark. After additional three washing steps in PBS, a solution of 4',6-Diamidino-2-Phenylindole, Dihydrochloride (DAPI, Thermo Fischer Scientific D1306) diluted 35,000-fold in PBS was used and it was left to act for 10 minutes at RT in the dark to color the nuclei. Images were obtained using an automated upright microscope system (Leica DM5500 B) coupled with Leica Cytovision software.

\section{Statistical Analyses}

All statistical analyses were performed using the Graphpad Prism 6 (Graphpad Software, Graphpad Holdings, LLC, CA, USA). Numbers of biological and/or technical replicates, as well as a description of the statistical parameters, are stated in the figure legends. All experimental images 
are representative of at least two independent experiments. For statistical significance, a p-value less than 0.05 was considered, unless otherwise specified.

\section{Results and Discussion}

Classical administrations of active pharmaceutical ingredients (APIs) are affected by issues related to systemic toxicity, drug chemical instability and repeated dosing requirement. As previously mentioned, HGs offer convenient drug delivery approaches, allowing them to overcome these drawbacks thanks to their tunable features, modular degradability and easy formulation. Macroscopically, hydrogel-based materials belong to two different categories based on their size: hydrogels (HGs) and nanogels (NGs). The specific size-feature determines the route of administration: transepithelial drug delivery or in situ gelation process of implants for HGs and systemic, oral and pulmonary administration of APIs for nanogels. ${ }^{46}$ The knowledge about the encapsulation procedures, the efficiency of drugs loading, and the cytotoxicity profiles can steer the development of efficient vehicles. For instance, swollen HGs matrices can be loaded in different ways, acting at macroscopic level, on the fibrillary network, the mesh size or at molecular scales. Moreover, the drug release can be differently modulated according to covalent or non-covalent approaches, in which drug molecules are chemically bound on the HG matrix by stable or cleavable linkers, or they can establish electrostatic interactions with HGs building blocks. These different drug loading strategies could affect the experimental conditions of preparation (eg, solvents, $\mathrm{pH}$ and salt content) and in turn the biological profile of the resulting vehicle. In this perspective, comparative studies on analogies and differences between HGs and NGs may assume a great importance.

\section{Formulation and Characterization of Dox Filled HGs}

HGs filled with the anticancer drug Dox were prepared according to the "solvent-switch" method. ${ }^{41}$ This method consists of the addition of an aqueous solution of Dox directly into the stock peptide solution $(100 \mathrm{mg} / \mathrm{mL}$ in DMSO). After few seconds of vortex, the resulting opaque metastable mixture is vertically incubated at room temperature until the formation of a limpid, translucent selfsupportive hydrogel. Dox filled hydrogels Fmoc-FF/(FY)3 and Fmoc-FF/PEG - $_{8}(\mathrm{FY}) 3$ at two different ratios $(1 / 1$ or $2 /$
$1, \mathrm{v} / \mathrm{v}$ ) were successfully formulated. Instead, in the same experimental conditions, Dox filled Fmoc-FF hydrogel appears not completely homogenous (see Figure S1). On the other hand, we observed a progressive improvement of the hydrogel homogeneity by increasing the amount (up to $0.018 \mathrm{~mol} \mathrm{~L}^{-1}$ ) of Dox to encapsulate (Figure S1). This behavior could be attributed to a shield effect of the charges occurring between the drug and the peptidic matrix. Although Dox filled Fmoc-FF hydrogel can be prepared, the Dox concentration is too high compared with mixed HGs and, for this reason, we did not further focus our attention on this sample. For mixed HGs, no syneresis was detected after 10 days. This specific no water-loss is an important advantage offered by HGs, thus allowing a precise modulation of water-soluble drug loaded in the system. According to this experimental evidence, we can assume that all the Dox was efficiently and quantitatively entrapped in the hydrogel matrix.

The resulting Dox filled hydrogels were further characterized in their xerogel form by confocal microscopy. Confocal images of one sample (Fmoc-FF/(FY)3, 1/1) are reported in Figure 2A and B. These images clearly show the characteristic intricate network of entangled fibers, ${ }^{47}$ and their red color suggests the tight interaction of Dox with the network constituents. The amount of drug we were able to encapsulate in mixed HGs was $2.32 \mathrm{mg} / \mathrm{mL}$. This quantity corresponds to a drug loading content (DLC) of 0.440 and to an encapsulation ratio (ER\%, defined as the weight percentage of drug encapsulated in the HG on the total drug added during preparation) of $100 \%$, respectively. This high encapsulation degree can be explained as consequence of the electrostatic interactions between the positive charge on the drug and the negative one present on the C-terminus of the Fmoc-FF peptide. Analogously to free Dox, also Doxil was efficiently encapsulated into mixed hydrogels at the same drug concentration. This is surprising due to the negative $\mathrm{Z}$ potential value (see Figure $\underline{\mathrm{S} 2})$ we measured for Doxil $(\zeta \sim-11 \mathrm{mV})$ into the experimental conditions $\left([\mathrm{Dox}]=1.13 \mathrm{mmol} \mathrm{L}^{-1}\right)$ used to achieve the encapsulation into the hydrogel.

A macroscopic evaluation of the gelation kinetics for mixed drug-filled hydrogels can be done by simply following the opaque-to-transparent optic transition. As previously observed for the corresponding empty systems, a different time (between 20 and 40 minutes) is required for the gelation process of each mixed hydrogel. ${ }^{38}$ In particular, we observed a more rapid formation for mixed HGs containing $\mathrm{PEG}_{8}-(\mathrm{FY}) 3$ (24 and 30 minutes for 2/1 

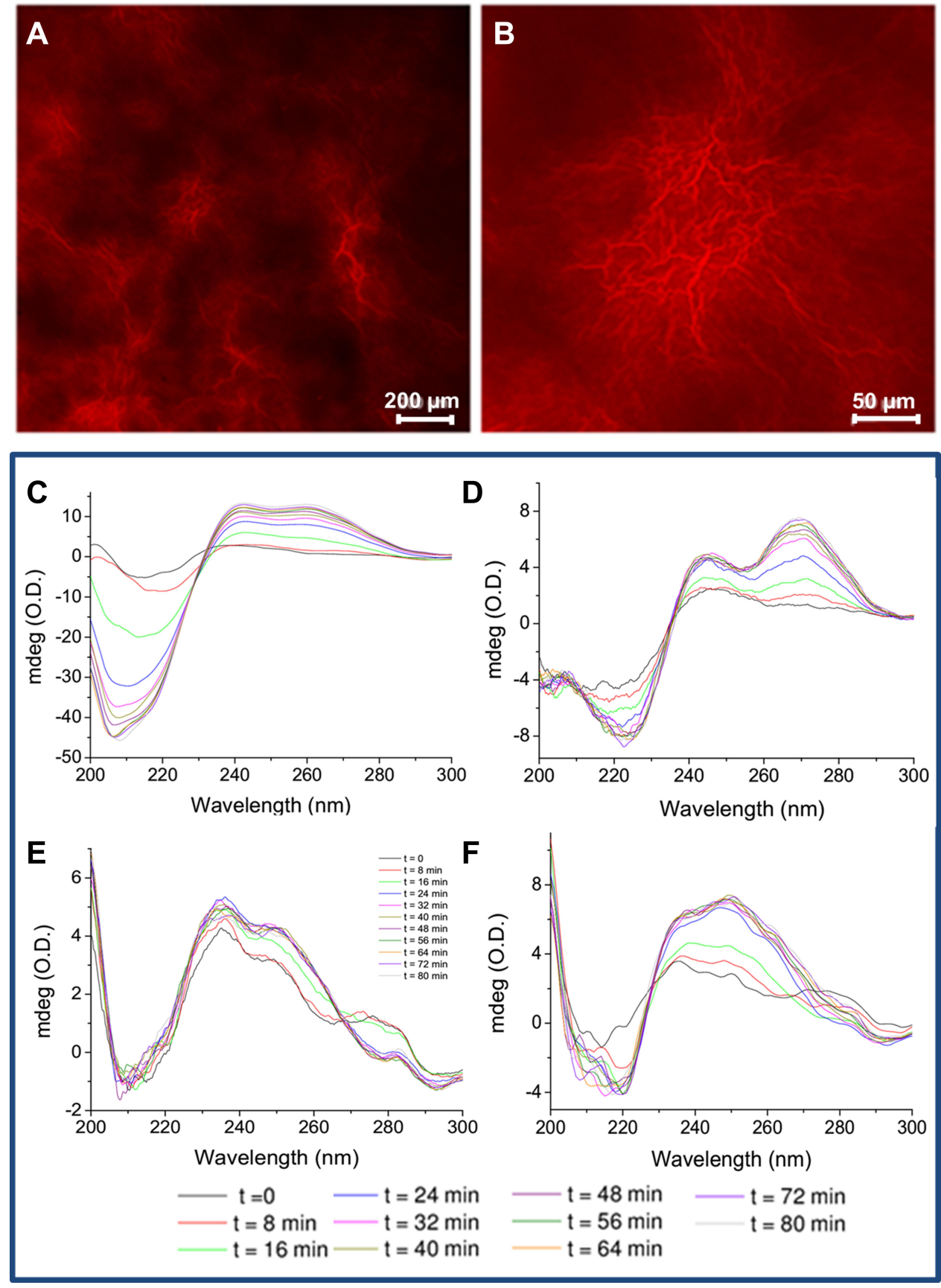

Figure 2 Characterization of mixed HGs. (A and B) Confocal microscopy image of Fmoc-FF/(FY)3 (I/I) xerogel loaded with Dox. Scale bar 200 (A) and 50 um (B), respectively. $\mathrm{CD}$ spectrum of $\mathrm{Fmoc}-\mathrm{FF} /(\mathrm{FY}) 3(\mathrm{I} / \mathrm{I})$ loaded with Dox in the visible region between 600 and $400 \mathrm{~nm}$. CD spectra of DOX filled co-assembled hydrogels FmocFF/(FY)3 (2/I) (C) Fmoc-FF/(FY)3 (I/I) (D) Fmoc-FF/PEG $-(F Y) 3(2 / I)(E)$ and Fmoc-FF/PEG $-(F Y) 3(I / I)(F)$ as function of the time.

and $1 / 1$, respectively) with respect to those containing (FY)3 (35 and 40 minutes for $2 / 1$ and $1 / 1$, respectively). Analogously to empty matrices, the gelation kinetics of Dox filled HGs is faster by increasing the amount of the Fmoc-FF. This result may be ascribable to the capability of Fmoc-FF to gelificate in a very quick time $(\sim 2 \mathrm{~min}) .{ }^{35} \mathrm{On}$ the contrary, we observe a faster gelation for HGs containing PEG in respect to HGs lacking polymer. This result is probably due to the additional interactions occurring between the hydrophilic PEG structure and the hydrophilic daunosamine moiety of Dox. As an alternative, gelation kinetics of hydrogels can be more accurately determined by following other structural or mechanical transitions occurring over time, related to alteration of UV-Vis absorbance, storage modulus $\left(G^{\prime}\right)$ or the dichroic signal. ${ }^{48}$ In this perspective, we recorded the CD spectra of Dox filled 
hydrogels at several time points in the spectral region between 300 and $200 \mathrm{~nm}$ (see Figure 2C-F). From the inspection of all the $\mathrm{CD}$ spectra, it clearly appears an evolution of the dichroic signal towards a stable state, in which we can assume that the HG has reached its final arrangement. The co-existence of several conformational states in the solution is also confirmed by isosbestic points between 220 and $240 \mathrm{~nm}$ and around $267 \mathrm{~nm}$ for $\mathrm{PEG}_{8}$ -(FY)3 containing HGs. By plotting the optical density (OD) in the relative minima for each sample, we were able to extrapolate the gelation times (see Figure S3). These times, evaluated from the CD measurements, were found in good agreement with the gelation times observed following the transition from the opaque to limpid form.

\section{Formulation and Characterization of Dox Filled NGs}

The preparation of pure Fmoc-FF and mixed nanogels loaded with Dox was achieved according to the top-down methodology. ${ }^{41}$ In this approach, macroscopic discs of hydrogels $(1.0 \% \mathrm{wt})$ loaded with Dox $\left(0.018 \mathrm{~mol} \mathrm{~L}^{-1}\right)$ were prepared into silicone molds according to the abovedescribed protocol. Successively, these discs were homogenized into an aqueous solution of TWEEN ${ }^{\circledR} 60$ (polyethylene glycol sorbitan monostearate) and SPAN ${ }^{\circledR} 60$ (Sorbitan stearate) as stabilizing agents. The combination of this couple of surfactants permits to achieve a hydrophilic/lipophilic balance (HLB) value ranged between 4.7 and 14.9. Due to the similar behavior exhibited by the four mixed HG formulations in terms of DLC and stability, we decided to prepare only one of the four mixed formulations, ie, Fmoc-FF/(FY)3 $(1 / 1, v / v)$. The best Dox filled NG formulations, in terms of size and stability, were obtained using TWEEN $^{\circledR} 60$ / $\operatorname{SPAN}^{\circledR} 60$ at $58 / 42$ ratio $(\mathrm{HLB}=10)$ or at $100 / 0$ ratio $(\mathrm{HLB}=14.9)$ for pure Fmoc-FF and mixed Fmoc-FF/(FY)3 $(1 / 1, v / v)$, respectively. Indeed, contrarily to the pure FmocFF formulation, the mixed one was found unstable when prepared with a value of HLB $=10$. The resulting suspensions, further submicronized using tip sonicator, were purified from free drug using size exclusion chromatography. The red coloration of purified formulations macroscopically suggested the incorporation of the anthracycline in the NGs vehicle. Due to its spectroscopic features $\left(\lambda_{\mathrm{abs}}=480 \mathrm{~nm} ; \lambda_{\mathrm{em}}\right.$ $=560,590 \mathrm{~nm}$ ), the amount of Dox encapsulated was analytically monitored and evaluated by UV-Vis spectroscopy, by checking the absorbance in the maximum at $\lambda_{\mathrm{abs}}=480 \mathrm{~nm}$. DLC and ER\% values for pure Fmoc-FF nanogel were
$0.137 \%$ and $63 \%$, respectively. This DLC value is similar to that of the commercially available liposomal formulations Myocet (DLC $=0.127$ ) and Doxil (DLC $=0.250)$. Therefore, the insertion of (FY)3 peptide in the preparation causes a slight decrease of both the DLC (0.093) and the ER\% $(45 \%)$ with respect to the pure formulation. The lower encapsulation degree observed for mixed NGs versus pure ones can be explained considering the different amount of the net negative charge present in the two nanogels. Indeed, the peptide (FY)3 has an amidated C-terminus, significantly less acidic compared to the carboxylic one, and a basic non protected $\mathrm{N}$-terminal amino group that can support a positive charge after protonation. This latter phenomenon contributes to the reduction of the total negative charge in the inner sphere of NGs, which determines lower attractive forces between the drug and the peptide system. The size of empty and filled Fmoc-FF/(FY)3 NGs, measured by Dynamic Light Scattering (DLS), was 168 and $214 \mathrm{~nm}$, respectively (see Figure 3 ). This increase in size $(\sim 22 \%)$ is comparable to the increase of dimensions previously observed for empty $(174 \mathrm{~nm})$ and filled $(241 \mathrm{~nm})$ Fmoc-FF NGs.

\section{Drug Release from HGs and NGs}

Drug release from both hydrogels and nanogels was evaluated in $0.100 \mathrm{~mol} \mathrm{~L}^{-1}$ phosphate buffer solution up to 72 hours and the corresponding release profiles are reported in Figure 4A and B, respectively. Two different procedures were used for determination of Dox release from hydrogels and nanogels. In the first case, Dox or Doxil filled hydrogels, prepared into a conic tube, were directly put in contact with a double volume of physiological solution,

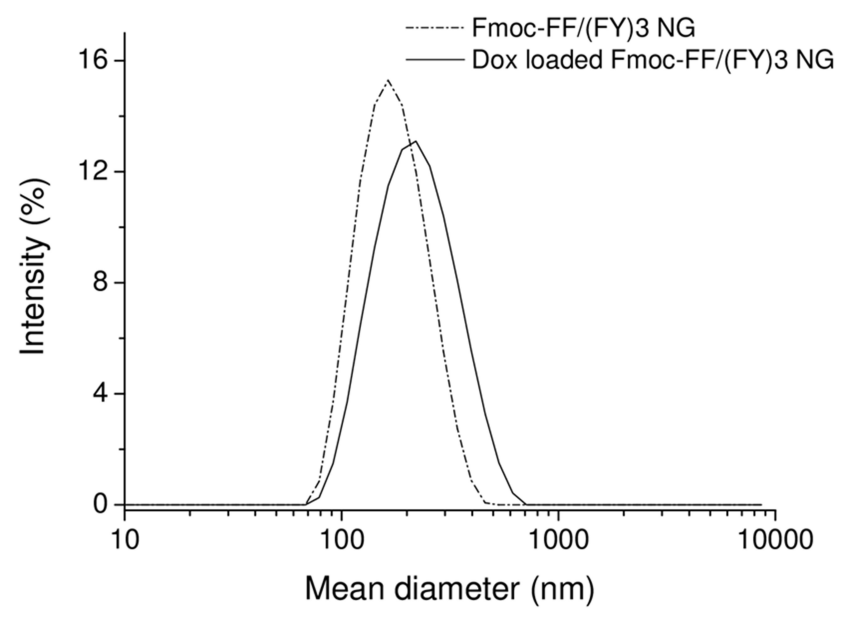

Figure 3 DLS profiles for empty and Dox filled Fmoc-FF/(FY)3 (I/I, v/v) nanogels prepared according to the top-down method. 


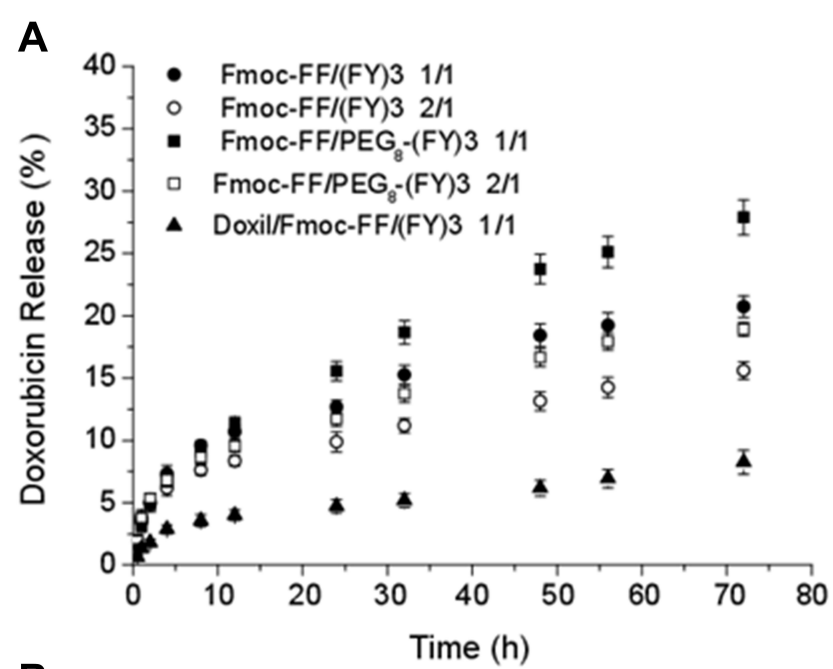

B

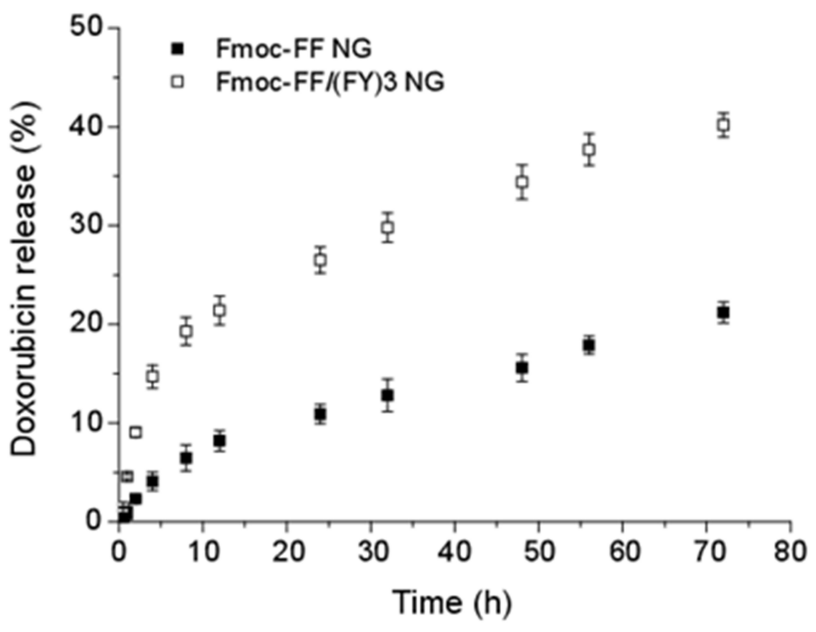

Figure 4 Drug release profiles for: (A) multicomponent Fmoc-FF/(FY)3 and FmocFF/PEG8-(FY)3 hydrogels up 72 hours; (B) pure Fmoc-FF and mixed Fmoc-FF/(FY)3 $(\mathrm{I} / \mathrm{I}, \mathrm{v} / \mathrm{v})$ nanogels.

cyclically replaced with a fresh one. Instead, in the second case, the release of Dox from nanogels was studied using a dialysis membrane immersed in phosphate buffer at $37^{\circ}$ C. We assumed that the crossing of the free Dox through the dialysis membrane occurred quickly, thus, the overall release of the free drug from the peptide-based nanostructures to the dialysis bag medium could be considered to be rate determining for the process. The API release from the systems was considered undergone to a diffusion process. The Dox amount released was estimated by UV-Vis (at $\lambda_{\mathrm{abs}}=480 \mathrm{~nm}$ ) or by fluorescence spectroscopies (at $\lambda_{\mathrm{em}}=$ $590 \mathrm{~nm}$ ) for HGs and NGs, respectively. The extent of drug was reported as a percentage of the ratio between the amount of released drug and the total drug initially loaded. From the inspection of Figure 4A, we can observe a similar release profile for all the Dox filled hydrogels during the first 24 hours. However, after 72 hours, each mixed gel exhibits a different release, with the lowest one for Fmoc-FF/(FY)3 (2/1) (16\%). A low drug release (21\%) was also observed for the other mixed HGs Fmoc-FF/(FY) $3(1 / 1)$. The same trend was also observed for the $\mathrm{PEG}_{8}$ -(FY)3 containing hydrogels with a release of $19 \%$ and $28 \%$ for $2 / 1$ and $1 / 1$ ratios, respectively. These results agree with our expectations that PEGylation of the peptide could affect the rigidity and permeability of the hydrogels matrix and, in turn, the drug release. As expected, the amount of drug released from the hydrogel encapsulating Doxil ( $\sim 8.5 \%)$ was lower than the drug released from the corresponding hydrogel $(21 \%)$. In Figure 4B is reported the Dox release (\%), which after $72 \mathrm{~h}$, is around $20 \%$ and $40 \%$ for pure Fmoc-FF and mixed Fmoc-FF/(FY)3 (1/ $1, \mathrm{v} / \mathrm{v}$ ) nanogels, respectively. Analogously to $\mathrm{HGs}$, also for NGs the drug release is more appreciable during the first $8-12 \mathrm{~h}$. The higher release observed for mixed NGs with respect to pure ones can be interpreted as a direct consequence of the lower electrostatic interactions occurring between the NG and the drug.

\section{Cytotoxicity Assays}

Cytotoxicity of mixed Fmoc-FF/(FY)3 (1/1, v/v) hydrogel encapsulating Dox or its liposomal formulation Doxil, at the same Dox concentration, was evaluated after 24 hours of incubation on MDA-MB-231 breast cancer cell line, using MTT assay. The cytotoxicity of the free drug, as well as of the empty hydrogels, was studied in the same conditions. HGs preparation was directly achieved into the hollow plastic chamber sealed at one end with a porous membrane. This experimental setting for hydrogels allows to mimic its conditions of utilization, in which this biocompatible support loaded with the chemotherapeutic agent is grafted at the level of the tumor lesion, where a controlled and constant drug release is achieved. During our experiments, hydrogels remain in contact with the cells for all the duration of the treatment. As shown in Figure 5A, the cell viability of empty hydrogels was found to be more than $95 \%$. This percentage of cell survival is similar to that previously observed by us for Fmoc-FF and Fmoc-FF/(FY)3 hydrogels co-incubated with the Chinese Hamster Ovarian (CHO) cell line. ${ }^{38}$ Dox loaded hydrogels significantly reduced viability of MDA-MB-231 cells after only $24 \mathrm{~h}$ of incubation (49\%) as well as free Dox at a concentration of $1 \mu \mathrm{mol} \mathrm{L}{ }^{-1}$ (55\%). This Dox concentration corresponds to its $\mathrm{IC}_{50}$ on MDA-MB-231 cells (see Supplementary Figure S4). Due to its lower drug release, 
A
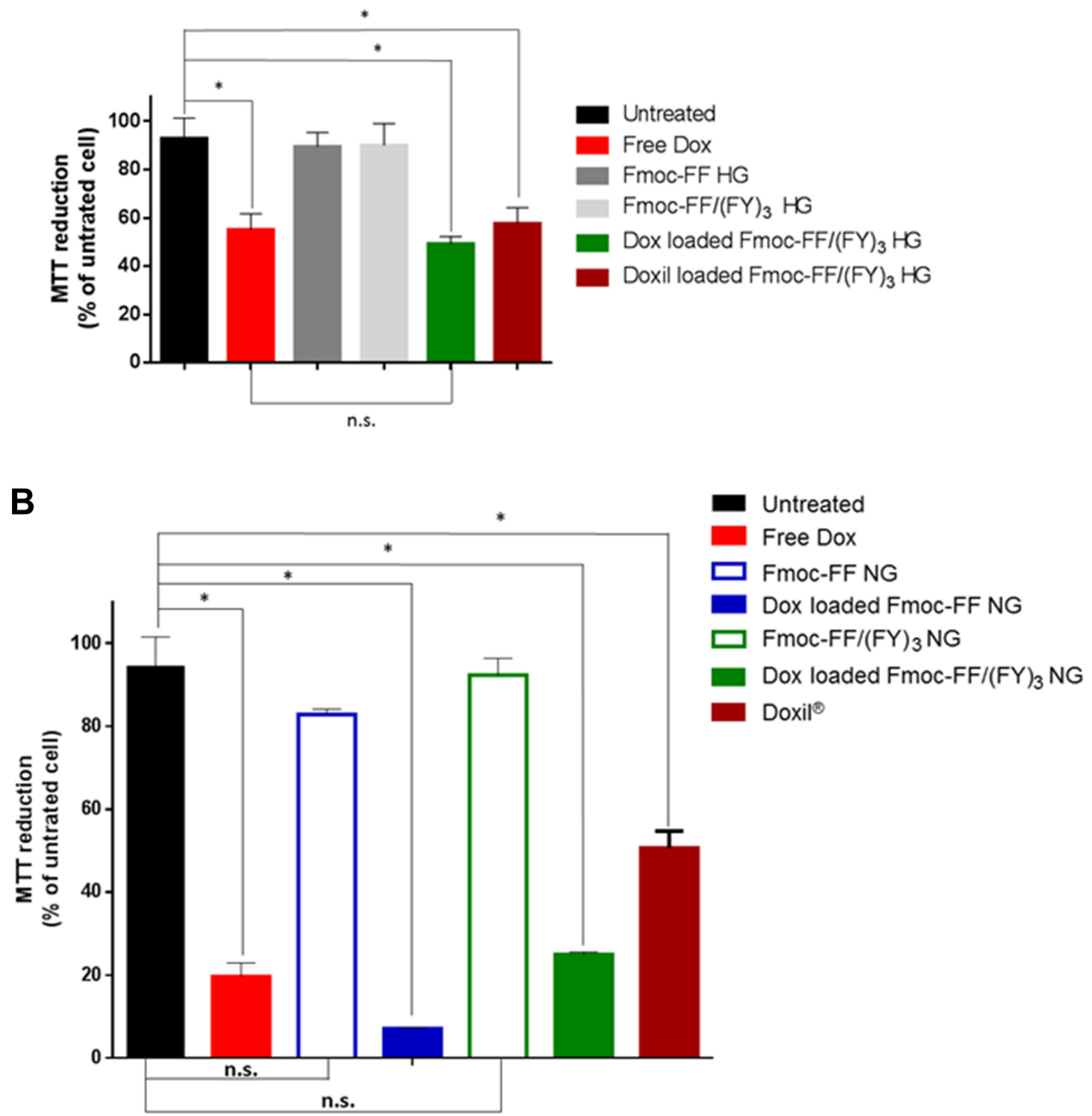

Figure 5 MDA-MB-23I cell survival after doxorubicin treatments. (A) MTT assay was conducted on MDA-MB-23I cells treated for $24 \mathrm{~h}$ with I $\mu$ mol $\mathrm{L}^{-1}$ of free Dox (red bar), empty Fmoc-FF HG (gray bar), empty Fmoc-FF/(FY)3 (I/I, v/v) HG (light gray bar), mixed Fmoc-FF/(FY)3 (I/I, v/v) HG loaded with Dox (green bar) and loaded with Doxil (burgundy bar) in comparison with untreated cells (black bar). Cell survival was expressed as percentage of viable cells in the presence of hydrogels, compared to control cells grown in their absence. (B) MTT assay was conducted on MDA-MB-23I cells treated for $72 \mathrm{~h}$ with $1 \mu \mathrm{mol} \mathrm{L}^{-1}$ of free Dox (red bar), empty Fmoc-FF NG (blue empty bar), empty Fmoc-FF/(FY)3 (I/I, v/v) NG (green empty bar), Dox loaded Fmoc-FF nanogels (blue fill bar), Dox loaded mixed Fmoc-FF/(FY)3 (I/I, v/v) NG (green fill bar) and Doxil (burgundy bar) in comparison with untreated cells (black bar). Cell survival was expressed as percentage of viable cells in the presence of hydrogels and nanogels compared to control cells grown in their absence (Error represents SD of four independent experiments. ${ }^{*} \mathrm{p}$-value $<0,05$. Mann-Withey $t$-test).

Abbreviation: n.s., not significant.

hydrogels encapsulating Doxil showed a slightly lower cytotoxicity, with a cell viability of $57 \%$.

On the other hand, Figure 5B reports the cell viability of the same cell line treated with pure Fmoc-FF and mixed Fmoc-FF(FY) $)_{3}$ nanogels, empty or loaded with the drug, in comparison to free Dox and Doxil. Initially, we evaluated the cytotoxicity of empty nanogels as function of the total peptide concentration at three different time points (24, 48 and $72 \mathrm{~h})$. We observed that there is a significant decrease in the cell viability during the first $48 \mathrm{~h}$ of incubation with nanogels. After this time of incubation, cell viability improves during the next $24 \mathrm{~h}$ (see Figure S5). This effect may be due to a temporary inhibition of the cell cycle induced by nanogels.
Based on these results, cytotoxicity of NGs encapsulating Dox was checked after $72 \mathrm{~h}$ of incubation. Analogously to HGs, Dox loaded nanogels are able to significantly reduce breast cancer cells viability, with a cell viability of $7 \%$ and $25 \%$ for pure and mixed hydrogels, respectively. The higher cytotoxicity of pure $\mathrm{HG}$ with respect to the mixed one is probably attributable to the intrinsic toxicity of the empty gel.

\section{Determination of the Cellular Uptake by Immunofluorescence}

The intracellular internalization of Dox loaded HGs and NGs was assessed using immunofluorescence analysis on 
MDA-MB-231 cells treated for $24 \mathrm{~h}$. Internalization of free Dox and Doxil are also reported for comparison. As indicated by the overlapping of red fluorescence associated to Dox with blue signal associated to DAPI (nucleus), the free drug can internalize into the nucleus after $24 \mathrm{~h}$ of incubation at $37^{\circ} \mathrm{C}$ (Figure 6A). Differently, Dox loaded Fmoc-FF/(FY)3 mixed hydrogel induces the internalization of Dox at peri-nuclear level since Dox signal is not perfectly overlapped with DAPI, but it is also partially detectable in the cytoplasm together with the green Actin signal (Figure 6B). The same behavior was previously observed for other liposomal Dox formulations. ${ }^{4,50}$ At the same time, doxorubicin conveyed through the nanogels remains in the cytoplasm of treated cells (Figure 6C), whereas by using Doxil the drug diffuses equally between the cytoplasm and the nucleus (Figure 6D). The different intracellular distribution of the drug in Figure 6 suggests an internalization mechanism alternative to the diffusion for the drug delivered by supramolecular systems like HGs, NGs and liposomes. One of the most accredited hypotheses is that nanogels are able to bind themselves primarily to the cellular membrane and then to enter the tumor cell via the endocytosis pathway. ${ }^{51,52}$

\section{Conclusion}

The administration of drugs is often affected by several issues related to systemic toxicity, chemical instability and repeated dosing requirement. Hydrogels and nanogels can represent alternative drug delivery vehicles to conventional supramolecular structures, such as vesicles, liposomes and nanostructures already developed and in clinical use. Indeed, macroscopic tridimensional $\mathrm{HG}$ networks could allow
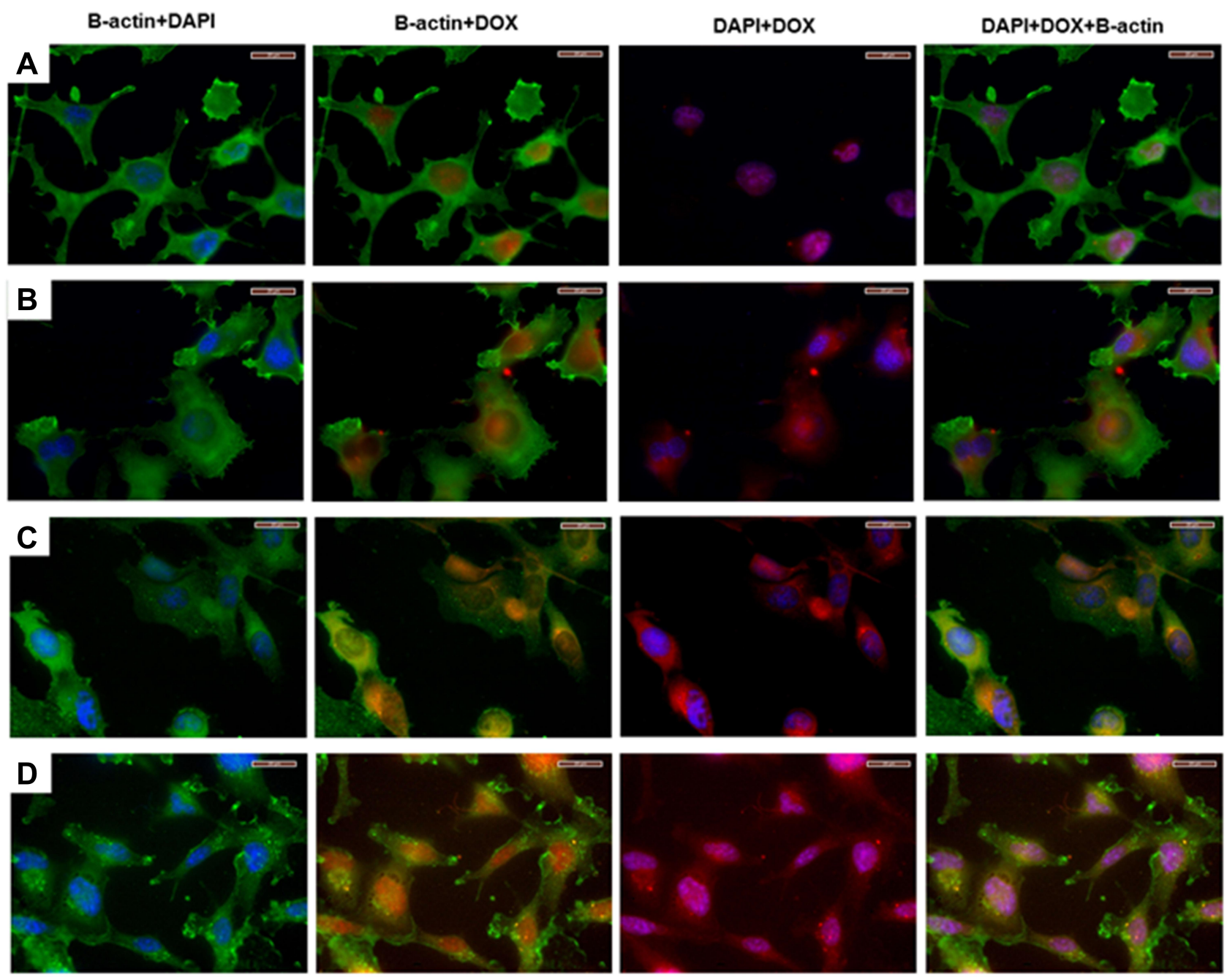

Figure 6 Immunofluorescence assay on cells. MDA-MB-23I cells treated with: (A) free Dox; (B) Dox loaded mixed Fmoc-FF/(FY)3 (I/I, v/v) HG; (C) Dox loaded Fmoc$\mathrm{FF} /(\mathrm{FY})_{3}(\mathrm{I} / \mathrm{I}, \mathrm{v} / \mathrm{v}) \mathrm{NGs}$ and (D) Doxil. Column I corresponds to Nuclei (DAPI, blue) and B-actin (FITC, green) staining. Column II corresponds to II $\beta$-actin (FITC, green) and doxorubicin (red) staining. Column III corresponds to Nuclei (DAPI, blue) and doxorubicin (red) staining. Column IV corresponds to Overlapping of FITC, PE and DAPI channels. Magnification $63 \times$. Scale bars $20 \mu \mathrm{m}$. 
transepithelial drug delivery or in situ gelation process for the formation of implants, whereas nanosized nanogels could be used for systemic, oral and pulmonary administration of drugs. Due to their high biocompatibility, good biodegradability and tunability, short or ultra-short peptides represent potential attractive alternatives for preparation of HGs and NGs with respect to natural and synthetic polymers. The peptide-based HGs and NGs here formulated are obtained by using the wellknown hydrogelator Fmoc-FF alone or in combination with (FY)3 peptide or its PEGylated analogue $\mathrm{PEG}_{8}-(\mathrm{FY}) 3$ at two different ratios. NGs were prepared starting from the corresponding HGs using a top-down approach in which the macroscopic hydrogel is submicronized and stabilized with commercially available biocompatible surfactants. Due to the common structure of their inner peptidic network, both NGs and HGs allow to efficiently encapsulate Dox. The gelation kinetics (from 24 to 40 minutes) and the drug release (16$28 \%$, after $72 \mathrm{~h}$ ) from hydrogels are clearly influenced by the hydrogel peptide composition. Analogously, the DLC values ( 0.137 and 0.093 for pure and mixed NGs, respectively) and the release percentages $(20-40 \%$, after $72 \mathrm{~h})$ in NGs are affected by their composition in terms of net charges. Cytotoxicity assays carried out on MDA-MB-231 breast cancer cell line pointed out a high cell viability $(>95 \%)$ for empty HGs and NGs, and a reduced cell viability (49-57\%) for Dox loaded HGs and NGs. Moreover, immunofluorescence assays show a different cellular localization for the Dox delivered by HGs and NGs with respect to the free Dox. Indeed, contrarily to the free Dox, localized in the nucleus, HGs and NGs allow internalization of the drug at the peri-nuclear level and in the cytoplasm, respectively. This result suggests a different internalization mechanism and a different intracellular distribution and Dox release between free Dox and Dox loaded in hydrogels/nanogels. All the in vitro data we collected and analyzed for pure Fmoc-FF and mixed Fmoc-FF/(FY)3 nanogels loaded with Dox suggest their potential use in vivo, by systemic administration, to deliver the cytotoxic drug on tumor tissues and cells. Thanks to its characteristics the new Dox loaded peptide supramolecular systems here described could be considered as promising valid alternatives to the already available liposomal Dox formulations.

\section{Acknowledgments}

This work was supported by the Italian Ministry of HealthRicerca Corrente project, by the PRIN-2017A2KEPL project and by the grant from Regione Campania-POR Campania FESR 2014/2020 “Combattere la resistenza tumorale: piattaforma integrata multidisciplinare per un approccio tecnologico innovativo alle oncoterapieCampania Oncoterapie" (Project No. B61G18000470007).

\section{Disclosure}

The authors report no conflicts of interest in this work.

\section{References}

1. Siegel RL, Miller KD, Jemal A. Cancer statistics, 2020. CA Cancer J Clin. 2020;70(1):7-30. doi:10.3322/caac.21590

2. Poustchi F, Amani H, Ahmadian Z, et al. Combination therapy of killing diseases by injectable hydrogels: from concept to medical applications. Adv Healthcare Mater. 2020;2001571.

3. McGowan JV, Chung R, Maulik A, Piotrowska I, Walker JM, Yellon DM. Anthracycline chemotherapy and cardiotoxicity. Cardiovasc Drugs Ther. 2017;31(1):63-75. doi:10.1007/s10557-016-6711-0

4. Carvalho C, Santos R, Cardoso S, et al. Doxorubicin: the good, the bad and the ugly effect. Curr Med Chem. 2009;16(25):3267-3285. doi:10.2174/092986709788803312

5. Falcone G, Filippelli W, Mazzarella B, et al. Cardiotoxicity of doxorubicin: effects of 21-aminosteroids. Life Sci. 1998;63 (17):1525-1532. doi:10.1016/S0024-3205(98)00419-6

6. Unverferth DV, Fertel RH, Talley RL, Magorien RD, Balcerzak SP. The effect of first-dose doxorubicin on the cyclic nucleotide levels of the human myocardium. Toxicol Appl Pharmacol. 1981;60 (1):151-154. doi:10.1016/0041-008X(81)90145-9

7. Falciani C, Accardo A, Brunetti J, et al. Target-selective drug delivery through liposomes labeled with oligobranched neurotensin peptides. ChemMedChem. 2011;6(4):678-685. doi:10.1002/cmdc.20 1000463

8. Nik ME, Malaekeh-Nikouei B, Amin B, et al. Liposomal formulation of galbanic acid improved therapeutic efficacy of PEGylated liposomal doxorubicin in mouse colon carcinoma. Sci Rep. 2019;9(1):9527. doi:10.1038/s41598-019-45974-7

9. Joniec A, Sek S, Krysinski P. Magnetoliposomes as potential carriers of doxorubicin to tumours. Chem Eur J. 2016;22(49):17715-17724. doi:10.1002/chem.201602809

10. Haghiralsadat F, Amoabediny G, Sheikhha MH, et al. New liposomal doxorubicin nanoformulation for osteosarcoma: drug release kinetic study based on thermo and $\mathrm{pH}$ sensitivity. Chem Biol Drug Des. 2017;90(3):368-379. doi:10.1111/cbdd.12953

11. Lipowska-Kur SR, Trzebicka B, Dworak A, Dworak A. Preparation and characterization of doxorubicin nanocarriers based on thermoresponsive oligo(ethylene glycol) methyl ether methacrylate polymer-drug conjugates. Eur Pol J. 2018;109:391-401. doi:10.1016/j.eurpolymj.2018.10.008

12. Diaferia C, Gianolio E, Sibillano T, et al. Cross-beta nanostructures based on dinaphthylalanine Gd-conjugates loaded with doxorubicin. Sci Rep. 2017;7(1):307. doi:10.1038/s41598-017-00332-3

13. Jiang T, Zhang C, Sun W, et al. Doxorubicin encapsulated in TPGSmodified 2D-nanodisks overcomes multidrug resistance. Chem Eur J. 2020;26(11):2470-2477. doi:10.1002/chem.201905097

14. Saini M, Ghosh S, Kumar V, Roy P, Sadhu KK. Selective release of doxorubicin from cucurbit[8] uril stabilized gold supra-pyramid host at pH of small intestine. Chem Eur J. 2020;26(66):15150-15158. doi:10.1002/chem.202002048

15. Hashemzadeh H, Raissi H. Understanding loading, diffusion and releasing of doxorubicin and paclitaxel dual delivery in graphene and graphene oxide carriers as highly efficient drug delivery systems. Appl Surf Sci. 2020;500:144220. doi:10.1016/j.apsusc.2019.144220

16. Alinejad A, Raissi H, Hashemzadeh H. Development and evaluation of a $\mathrm{pH}$-responsive and water-soluble drug delivery system based on smart polymer coating of graphene nanosheets: an in silico study. RSC Adv. 2020;10(52):31106. doi:10.1039/D0RA06705A 
17. Okay O. General properties of hydrogels. In: Gerlach G, Arndt K-F, editors. Hydrogel Sensors and Actuators. Engineering and Technology. 2010:1-14.

18. Martino MM, Tortelli F, Mochizuki M, et al. Engineering the growth factor microenvironment with fibronectin domains to promote wound and bone tissue healing. Sci Transl Med. 2011;3(100):100ra89. doi:10.1126/scitranslmed.3002614

19. Hosoyama K, Lazurko C, Muñoz M, McTiernan CD, Alarcon EI. Peptide-based functional biomaterials for soft-tissue repair. Front Bioeng Biotechnol. 2019;7:205. doi:10.3389/fbioe.2019.00205

20. Klotz BJ, Oosterhoff LA, Utomo L, et al. A versatile biosynthetic hydrogel platform for engineering of tissue analogues. Adv Health Mater. 2019;8(19):1900979. doi:10.1002/adhm.201900979

21. Singh N, Kumar M, Miravet JF, Ulijn RV, Escuder B. Peptide-based molecular hydrogels as supramolecular protein mimics. Chem Eur J. 2016;23(5):981-993. doi:10.1002/chem.201602624

22. Alvarez-Lorenzo C, Anguiano-Igea S, Varela-García A, Vivero-Lopez M, Concheir A. Bioinspired hydrogels for drug-eluting contact lenses. Acta Biomater. 2019;84:49-62. doi:10.1016/j.actbio.2018.11.020

23. Karcher J, Pianowski ZL. Photocontrol of drug release from supramolecular hydrogels with green light. Chem Eur J. 2018;24 (45):11605-11610. doi:10.1002/chem.201802205

24. Daly AC, Riley L, Segura T, Burdick JA. Hydrogel microparticles for biomedical applications. Nat Rev Mater. 2020;5:20-43.

25. Lübtow MM, Lorson T, Gröber-Becker F-K, Luxenhofer R, Luxenhofer R. Combining ultra-high drug-loaded micelles and injectable hydrogel drug depots for prolonged drug release. Macromol Chem Phys. 2020;221(1):1900341. doi:10.1002/macp.201900341

26. Argentiere S, Blasi L, Ciccarella G, Barbarella G, Cingolani R, Gigli G. Synthesis of poly(acrylic acid) nanogels and application in loading and release of an oligothiophene fluorophore and its bovine serum albumin conjugate. Macromol Symp. 2009;281(1):69-76. doi:10.1002/masy.200950709

27. Dong L, Wang S-J, Zhao X-R, Zhu Y-F, Yu J-K. 3D-printed poly( $\varepsilon-$ caprolactone) scaffold integrated with cell-laden chitosan hydrogels for bone tissue engineering. Sci Rep. 2017;7(1):13421. doi:10.1038/ s41598-017-13838-7

28. Das D, Das R, Mandal J, Ghosh A, Pal S. Dextrin crosslinked with poly(lactic acid): a novel hydrogel for controlled drug release application. J Appl Polym Sci. 2014;131(7). doi:10.1002/APP.40039

29. Neves MI, Araújo M, Moroni L, da Silva RMP, Barrias CC. Glycosaminoglycan-inspired biomaterials for the development of bioactive hydrogel networks. Molecules. 2020;25(4):978. doi: $10.3390 /$ molecules 25040978

30. Suner SS, Ari B, Onder FC, Ozpolat B, Ay M, Sahine N. Hyaluronic acid and hyaluronic acid: sucrose nanogels for hydrophobic cancer drug delivery. Int J Biol Macromol. 2019;1(126):1150-1157. doi:10.1016/j.ijbiomac.2019.01.021

31. Wang H, Qian J, Ding F. Recent advances in engineered chitosan-based nanogels for biomedical applications. J Mater Chem B. 2017;5(34):6986-7007. doi:10.1039/C7TB01624G

32. Dibbert N, Krause A, Rios-Camacho J-C, Gruh I, Kirschning A, Dräger G. A synthetic toolbox for the in situ formation of functionalized homo- and heteropolysaccharide-based hydrogel libraries. Chem Eur J. 2016;22 (52):18777-18786. doi:10.1002/chem.201603748

33. Echalier C, Jebors C, Laconde G, et al. Sol-gel synthesis of collageninspired peptide hydrogel. Mater Today. 2017;20(2):59-66. doi:10.1016/j.mattod.2017.02.001

34. Ghosh M, Bera S, Schiffmann S, Shimon LJW, Adler-Abramovich L. Collagen-inspired helical peptide co-assembly forms a rigid hydrogel with twisted polyproline II architecture. ACS Nano. 2020;14 (8):9990-10000. doi:10.1021/acsnano.0c03085

35. Smith AM, Williams RJ, Tang C, et al. Fmoc-diphenylalanine self assembles to a hydrogel via a novel architecture based on $\pi-\pi$ interlocked $\beta$-sheets. Adv Mater. 2008;20(1):37-41. doi:10.1002/ adma.200701221
36. Diaferia C, Morelli G, Accardo A. Fmoc-diphenylalanine as a suitable building block for the preparation of hybrid materials and their potential applications. J Mater Chem B. 2019;7(34):5142-5155. doi:10.1039/C9TB01043B

37. Mahler A, Reches M, Rechter M, Cohen S, Gazit E. Rigid, selfassembled hydrogel composed of a modified aromatic dipeptide. $A d v$ Mater. 2006;18(11):1365-1370. doi:10.1002/adma.200501765

38. Diaferia C, Ghosh M, Sibillato $\mathrm{T}$, et al. Fmoc-FF and hexapeptide-based multicomponent hydrogels as scaffold materials. Soft Matter. 2019;15(3):487-496. doi:10.1039/C8SM02366B

39. Diaferia C, Balasco N, Sibillano T, et al. Amyloid-like fibrillary morphology originated by tyrosine-containing aromatic hexapeptides. Chem Eur J. 2018;24(26):6804-6817. doi:10.1002/chem.201800351

40. Foulkes WD, Smith IE, Reis-Filho JS. Triple-negative breast cancer. $N$ Engl J Med. 2010;363(20):1938-1948. doi:10.1056/ NEJMra1001389

41. Rosa E, Diaferia C, Gallo E, Morelli G, Accardo A. Stable formulations of peptide-based nanogels. Molecules. 2020;25(15):3455 doi: $10.3390 /$ molecules 25153455

42. Diaferia C, Balasco N, Altamura D, et al. Assembly modes of hexaphenylalanine variants as function of the charge states of their terminal ends. Soft Matter. 2018;14(40):8219-8230. doi:10.1039/ C8SM01441H

43. Diaferia C, Netti F, Ghosh M, et al. Bi-functional peptide-based 3D hydrogel-scaffolds. Soft Matter. 2020;16(30):7006-7017. doi:10.1039/D0SM00825G

44. Raeburn J, Mendoza-Cuenca C, Cattoz BN, et al. The effect of solvent choice on the gelation and final hydrogel properties of Fmoc-diphenylalanine. Soft Matter. 2015;11(5):927-935. doi:10.1039/C4SM02256D

45. Ringhieri P, Iannitti R, Nardon C, et al. Target selective micelles for bombesin receptors incorporating. $\mathrm{Au}(\mathrm{III})$-dithiocarbamato complexes. Int J Pharm. 2014;473(1-2):194-202. doi:10.1016/j. ijpharm.2014.07.014

46. Li J, Mooney DJ. Designing hydrogels for controlled drug delivery. Nat Rev Mater. 2016;1:16071.

47. Tang JD, Mura C, Lampe KJ. Stimuli-responsive, pentapeptide, nanofiber hydrogel for tissue engineering. $J$ Am Chem Soc. 2019;141(12):4886-4899. doi:10.1021/jacs.8b13363

48. Ghosg M, Halperin-Sternfeld M, Grigoriants I, Lee J, Nam KT, Adler-Abramovich L. Arginine-presenting peptide hydrogels decorated with hydroxyapatite as biomimetic scaffolds for bone regeneration. Biomacromol. 2017;18(11):3541-3550. doi:10.1021/ acs.biomac.7b00876

49. Accardo A, Arena F, Gianolio E, et al. Diolein based nanostructures as targeted theranostics. J Biomed Nanotechnol. 2016;12 (5):1076-1088. doi:10.1166/jbn.2016.2212

50. Tarallo R, Accardo A, Falanga A, et al. Clickable functionalization of liposomes with the gH625 peptide from Herpes simplex virus type I for intracellular drug delivery. Chem Eur J. 2011;17 (45):12659-12668. doi:10.1002/chem.201101425

51. Zhang H, Pei M, Liu P. pH-activated surface charge-reversal double-crosslinked hyaluronic acid nanogels with feather keratin as multifunctional crosslinker for tumor-targeting DOX delivery. Int $\mathrm{J}$ Biol Macromol. 2020;150:1104-1112. doi:10.1016/j.ijbiomac.2019.10.116

52. Chen X, Zhang X, Guo Y, et al. Smart supramolecular "trojan horse"inspired nanogels for realizing light-triggered nuclear drug influx in drug-resistant cancer cells. Adv Funct Mater. 2019;29(13):1807772. doi:10.1002/adfm.201807772 


\section{Publish your work in this journal}

The International Journal of Nanomedicine is an international, peerreviewed journal focusing on the application of nanotechnology in diagnostics, therapeutics, and drug delivery systems throughout the biomedical field. This journal is indexed on PubMed Central, MedLine, CAS, SciSearch ${ }^{\mathbb{B}}$, Current Contents ${ }^{{ }^{\mathbb{B}}} /$ Clinical Medicine,
Journal Citation Reports/Science Edition, EMBase, Scopus and the Elsevier Bibliographic databases. The manuscript management system is completely online and includes a very quick and fair peer-review system, which is all easy to use. Visit http://www.dovepress.com/ testimonials.php to read real quotes from published authors. 